\title{
Key genetic variants in the renin-angiotensin system and left ventricular mass in a cohort of Polish patients with heart failure
}

\author{
Iwona Gorący', Małgorzata Peregud-Pogorzelska², Krzysztof Safranow³, Andrzej Ciechanowicz \\ 'Department of Clinical and Molecular Biochemistry, Pomeranian Medical University, Szczecin, Poland \\ ${ }^{2}$ Clinic of Cardiology, Pomeranian Medical University, Szczecin, Poland \\ ${ }^{3}$ Department of Biochemistry and Medical Chemistry, Pomeranian Medical University, Szczecin, Poland
}

\section{Editorial}

by Palmer,

see p. 728

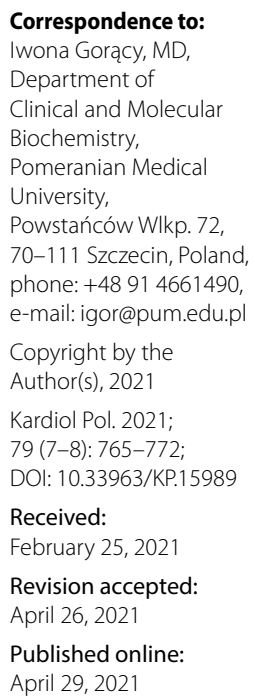

\begin{abstract}
A B STRACT
Background: Heart failure (HF) is a complex disease that is under the control of different physiological systems. Left ventricular mass (LVM) is a strong predictor of HF. The renin-angiotensin system (RAS) may contribute to the pathogenesis of HF and LVM.
\end{abstract}

Aims: The aim of this study is to examine the association between RAS genetic variants and HF and LVM in the cohort of Polish patients with HF.

Methods: The study included 401 patients with HF. Two-dimensional M-mode echocardiography was used to assess LVM. Genomic DNA was extracted from blood, and genotyping of the angiotensin-converting enzyme (ACE) (rs4646994), angiotensinogen ( $A G T$ ) (rs5051), and angiotensin II receptor type 1 (AGTR1) (rs5186) polymorphisms was carried out using polymerase chain reaction (PCR).

Results: A significant association was found between HF and the genotypes of $G(-6) A A G T$, and the homozygotes AA of $A G T$ were significantly less common in the HF vs control group. The results of this study did not confirm the relationship between $A G T, A C E$ and $A T 1 R$ genetic variants with LVM in Polish patients with HF.

Conclusions: Our results suggested that $A G T$ polymorphism may play a protective role in the development of HF.

Key words: genes, heart failure, left ventricular mass, renin-angiotensin system

Kardiol Pol 2021; 79, 7-8: 765-772

\section{INTRODUCTION}

Heart failure (HF) is a growing global health problem that is also responsible for high mortality. The most common causes of HF are ischemic heart disease (IHD), hypertension (HT), valvular heart disease (VD) or cardiomyopathy [1]. However, it is known that the etiology of HF is complex and researchers are still looking for factors that influence the development and progression of HF.

It is already known that the renin-angiotensin system (RAS) plays an important role in the pathophysiology of left ventricular (LV) dysfunction, left ventricular hypertrophy (LVH), regulation of arterial pressure, cardiovascular diseases, and thus, HF [2]. Angiotensinogen (AGT), angiotensin-converting enzyme $(A C E)$ and angiotensin II receptor type 1 (AGTR1) are key components of RAS. So far, researchers have shown that AGT polymorphisms are mainly associated with the development of $\mathrm{HT}$ or $\mathrm{IH}[3,4]$, while the correlations with HF remain inconsistent $[5,6]$. However, some studies indicate a correlation between AGT gene polymorphism and increased left ventricular mass (LVM) $[7,8]$, and LVH is a strong predictor of HF [9].

The insertion/deletion polymorphism (I/D) of the ACE gene is the most extensively studied and has been shown to be correlated with HT, IHD and other cardiovascular intermediate phenotypes [10-15]. Moreover, ACE has been known to have a crucial role in the development of cardiac 
WHAT'S NEW?

Heart failure (HF) is a major cause of morbidity and mortality in the world. The renin-angiotensin system (RAS) plays an important role in the pathophysiology of HF development and left ventricular dysfunction. Left ventricular mass (LVM) is a major contributor to the development of heart failure. The search for genetic variants that could act as prognostic markers that could be used to predict poor outcomes and assist in selecting appropriate therapy is still ongoing. To determine the relationship between the key RAS genetic variants: $G(-6) A$ angiotensinogen (AGT), insertion/deletion polymorphism of angiotensin-converting enzyme (I/D ACE) or A1166C angiotensin II receptor type 1 (AGTR1), and HF or LVM, we studied 401 Polish patients with HF. Our results suggested that AGT polymorphism may play a protective role in the development of HF.

remodeling by either angiotensin II or aldosterone [16]. There are some reports that suggest that this polymorphism is associated with increased LVM in normotensive and hypertensive patients or in patients with cardiomyopathy $[17,18]$, although there are studies that do not support this correlation $[19,20]$. While the genetic determinants of LVM in patients with HF have not been so extensively studied, the role of the I/D ACE polymorphism in shaping LVM is not fully understood. There is no direct reporting targeting of genetic predisposition to increase LVM in patients with $\mathrm{HF}$, and the role of I/D ACE polymorphism in LVM modulation may be significant, and thus, for HF may be of pivotal importance.

The effect of AGTR1 on the regulation of LVM was also demonstrated, as it was found to influence the regulation of blood volume and stimulate the growth and proliferation of heart cells, which causes the development of HF [21]. However, the results of available studies remain controversial and other studies were not able to detect any influence of RAS gene polymorphisms on LVM $[22,23]$. Although the potential role of the RAS system in structure and heart disorders is relatively well understood, these molecular mechanisms involved in LVM in patients with HF continue to be studied. Especially, RAS genetic polymorphisms involved in HF pathophysiology are of particular interest as the plausible candidates may play a role in modifying LVM.

Therefore, the aim of our study was to analyze the association between the G(-6)A AGT (rs5051), I/D ACE (rs4646994) and A1166C AGTR1 (rs5186) genetic variants and both HF and the LVM in a cohort of Polish patients with HF.

\section{METHODS}

\section{Patients}

This study was conducted in accordance with the Declaration of Helsinki and was approved by the local bioethics committee at the Pomeranian Medical University (PMU) in Szczecin, Poland. Written informed consent was obtained from study participants.

This was a case-control study of patients with a diagnosis of HF from Department of Cardiac Surgery and Cardiology Department of PMU. A total of 401 patients
(293 men, 108 women) included in the study had symptomatic HF, defined as New York Heart Association (NYHA) functional class I-IV. The study group with HF included patients with IHD ( $\mathrm{n}=245 ; 192$ men, 53 women), patients with VD ( $\mathrm{n}=68 ; 37$ men, 31 women), and patients with combined disease, IHD and VD ( $n=88 ; 64$ men, 24 women). Among these HF patients were 195 patients with reduced ejection fraction $<50 \%$ (HF with reduced ejection fraction [HfrEF] subgroup). Doppler echocardiography was used to examine LV dysfunction.

Demographic data and medical history of patients were collected from their medical chart records. The control group was consisted of 120 volunteers ( 43 men, 77 women) without history of cardiac disease.

\section{Echocardiography}

Transthoracic echocardiography was performed using an Acuson Sequoia 512 unit (Siemens, Munich, Germany) equipped with a 2-4 MHz imaging transducer, according to the recommendations of the American Society of Echocardiography (ASE). Measurements of LV end-diastolic diameter (LVEDD), LV septal wall thickness diameter (IVTd) and posterior wall thickness diameter (PWTd) were obtained in the M-mode parasternal long-axis view. An average of values after three image acquisitions was calculated. In cases with suboptimal M-mode acquisition, measurements in two-dimensional views were obtained instead. LVM was calculated with the ASE-recommended formula [24]: LVM $(\mathrm{g})=0.8 \times\{1.04$ [(LVEDD + PWTd + IVTd)3 - (LVEDD)3]\} + $0.6 \mathrm{~g}$. Body surface area was calculated using the Mosteller formula ssquare root [height $(\mathrm{cm}) \times$ weight $(\mathrm{kg})] / 3600\}$ and LVM was indexed to the body surface area. LVH was defined as LV mass index (LVMI) $>115 \mathrm{~g} / \mathrm{m}^{2}$ in men and $>95 \mathrm{~g} / \mathrm{m}^{2}$ in women [24].

\section{Genotyping}

Genomic DNA was isolated from whole blood collected into ethylenediaminetetraacetic acid tubes using the QIAamp Blood DNA Mini Kit (QIAGEN, Hilden, Germany).

For the analysis, a polymerase chain reaction and polymerase chain reaction/restriction fragments length polymorphism (PCR/RFLP) method were applied. Genotyping of the G(-6)A AGT (rs5051), I/D ACE (rs4646994) and 
A1166C AGTR1 (rs5186) polymorphisms were carried out as previously described [25].

\section{Statistical analysis}

The distributions of all quantitative variables, except age, were significantly different from normal distribution $(P<0.05$, Shapiro-Wilk's test). Therefore, quantitative variables were presented as the median with lower quartile and upper quartile, and analyzed using the non-parametric Kruskal-Wallis or the Mann-Whitney U test. Qualitative variables were presented as number with corresponding percentage and compared between groups with the chi-square or the Fisher exact test. Concordance of genotype distribution with Hardy-Weinberg equilibrium was performed with the exact test. Strength of association of qualitative variables with genotypes and alleles was described as odds ratio (OR) with $95 \%$ confidence interval $(95 \% \mathrm{Cl})$. Multivariable logistic regression analysis adjusted for age and sex was performed to verify whether the associations of genetic polymorphisms with HF are independent of these demographic factors. $P<0.05$ was considered statistically significant without correction for multiple tests. Bonferroni-corrected $P$-value thresholds were calculated as follows: for the study of associations between $\mathrm{HF}$ and each of the 3 polymorphisms in 4 models of inheritance (dominant, recessive or additive mode for minor allele as well as comparison of wild-type homozygotes with mutated ones), $3 \times 4=12$ tests were performed, so the corrected $P$-value threshold was $0.05 / 12=0.0042$; for the study of associations between LVMI and each of the 3 polymorphisms in 4 aforementioned models of inheritance in the whole group of HF patients and in the subgroups with arterial hypertension or with HFrEF, $3 \times 4 \times 3=36$ tests were performed, so the corrected $P$-value threshold was $0.05 / 36=0.0014$. Calculations were performed with Statistica 13 software (Statistica, Dell Inc. [2016], version 13, software.dell.com).

\section{RESULTS}

The baseline characteristics of the HF subjects is shown in Table 1. The BMI and age proved to be significantly higher in the HF group, when compared to controls. Similarly, smoking, diabetes, and $\mathrm{HT}$ were more common among HF patients than controls. Significant differences in all echocardiographic parameters were noted between HF patients and controls (higher IVT, PWT, LVM, LVMI, LVEDD and lower ejection fraction [EF] values in the HF group) (Table 1).

The G(-6)A AGT, I/D ACE and A1166C AGT1R gene polymorphism genotypes were found to be in Hardy-Weinberg equilibrium both in the HF and control group $(P>0.1)$. We observed a significant association between HF and genotypes of $\mathrm{G}(-6) \mathrm{A} A G T$ (Table 2). Analyses revealed that homozygotes AA of $A G T$ are significantly less common in the HF group than in the control group $(P=0.014)$. The negative association between AA AGT genotype and HF was even stronger in multivariable logistic regression model adjusted for age and sex (OR, 0.427; 95\% Cl, 0.245-0.742; $P=0.0025)$, reaching the Bonferroni-corrected $P$-value threshold $(<0.0042)$. No association was found between I/D ACE or A1166C AGT1R gene polymorphism and HF, both in univariable and multivariable analyses $(P>0.3)$.

The results of association of the $\mathrm{G}(-6) \mathrm{A} A G T, \mathrm{I} / \mathrm{D}$ ACE and A1166C AGT1R polymorphisms with LVMI in HF patients are summarized in Table 3. We did not detect any significant correlations. The results of these tests on the effects of $G(-6)$ A AGT, I/D ACE and A1166C AGT1R polymorphisms with $\mathrm{LVH}$ defined as LVMI $>115 \mathrm{~g} / \mathrm{m}^{2}$ in men and $>95 \mathrm{~g} / \mathrm{m}^{2}$ in women are presented in Table 4 . We did not find any significant correlations.

We also found no relationship between the studied polymorphisms and LVMI in the subgroup of patients with HF and arterial hypertension ( $\mathrm{n}=309 ; P>0.1$; data not shown).

Subsequently, we conducted an analysis of the effect of G(-6)A AGT, I/D ACE and A1166C AGT1R genotypes on LVH in a subgroup of HF patients with $\mathrm{HFrEF}<50 \%$ (Table 5).

Table 1. Clinical and echocardiographic characteristics of patients with HF and control group

\begin{tabular}{|c|c|c|c|}
\hline Characteristics & HF cases $(n=401)$ & Control $(n=120)$ & $P$-value ${ }^{a}$ \\
\hline Age, years & $66.0(61.0-71.0)$ & $56.0(49.0-63.0)$ & $<0.0001$ \\
\hline $\mathrm{BMI}, \mathrm{kg} / \mathrm{m}^{2}$ & $29.0(25.8-31.7)$ & $27.3(24.8-29.4)$ & $<0.0001$ \\
\hline Males & $293(73)$ & $77(64)$ & 0.077 \\
\hline Smoking & $126(31)$ & $24(20)$ & 0.021 \\
\hline Diabetes mellitus & $258(64)$ & $9(7)$ & $<0.0001$ \\
\hline Hypertension & $337(84)$ & $24(20)$ & $<0.0001$ \\
\hline \multicolumn{4}{|l|}{ Echocardiographic parameters } \\
\hline IVT, cm & $1.25(1.10-1.40)$ & $0.97(0.95-1.00)$ & $<0.0001$ \\
\hline PWT, cm & $1.10(1.00-1.25)$ & $1.05(1.00-1.10)$ & $<0.0001$ \\
\hline LVEDD, cm & $5.00(4.61-5.50)$ & $4.75(4.31-5.05)$ & $<0.0001$ \\
\hline$E F, \%$ & $50.0(40.0-55.0)$ & $64.0(62.0-67.2)$ & $<0.0001$ \\
\hline LVM, g & $241.8(195.9-293.8)$ & $171.5(147.9-190.3)$ & $<0.0001$ \\
\hline LVMI, $\mathrm{g} / \mathrm{m}^{2}$ & $125.7(99.3-149.5)$ & $88.8(76.0-102.5)$ & $<0.0001$ \\
\hline
\end{tabular}

Quantitative variables are presented as median (IQR) and qualitative data are presented as a number with corresponding percentage.

${ }^{\text {aT }}$ The Fisher exact test for qualitative variables and the Mann-Whitney $U$ test for quantitative variables.

Abbreviations: BMI, body mass index; EF, ejection fraction; HF, heart failure; IVT, left ventricular septal wall thickness; LVEDD, left ventricular end-diastolic diameter; LVM, left ventricular mass; LVMI, left ventricular mass index; PWT, posterior wall thickness 
Table 2. Genotype frequencies for G(-6)A AGT, I/D ACE, A1166C AGT1R in patients with HF and control group

\begin{tabular}{|c|c|c|c|c|c|c|c|c|}
\hline Polymorphism & \multicolumn{2}{|c|}{$\begin{array}{l}\text { HF group } \\
(n=401)\end{array}$} & \multicolumn{2}{|c|}{$\begin{array}{l}\text { Control group } \\
(n=120)\end{array}$} & $P$-value ${ }^{a}$ & $\begin{array}{c}\text { Compared genotypes or } \\
\text { alleles }\end{array}$ & OR $(95 \% \mathrm{Cl})$ & $P$-value ${ }^{b}$ \\
\hline \multicolumn{9}{|l|}{ AGT genotype } \\
\hline GG & 108 & $26.9 \%$ & 31 & $25.8 \%$ & \multirow[t]{3}{*}{0.042} & $A A+G A$ vs $G G$ & $0.945(0.594-1.504)$ & 0.811 \\
\hline GA & 215 & $53.6 \%$ & 53 & $44.2 \%$ & & $A A$ vs $G A+G G$ & $0.564(0.355-0.895)$ & $0.014^{c}$ \\
\hline $\mathrm{AA}$ & 78 & $19.6 \%$ & 36 & $30.0 \%$ & & AA vs GG & $0.622(0.355-1.091)$ & 0.096 \\
\hline \multicolumn{9}{|l|}{$A G T$ allele } \\
\hline G & 431 & $53.7 \%$ & 115 & $47.9 \%$ & - & \multirow[t]{2}{*}{ A vs $G$} & $0.792(0.593-1.057)$ & \multirow[t]{2}{*}{0.113} \\
\hline A & 371 & $46.3 \%$ & 125 & $52.1 \%$ & - & & & \\
\hline \multicolumn{9}{|l|}{ ACE genotype } \\
\hline$\|$ & 92 & $22.9 \%$ & 27 & $22.5 \%$ & \multirow[t]{3}{*}{0.99} & $\mathrm{DD}+\mathrm{ID}$ vs II & $0.975(0.599-1.588)$ & 0.919 \\
\hline ID & 207 & $51.6 \%$ & 62 & $51.7 \%$ & & DD vs ID + II & $0.979(0.614-1.562)$ & 0.930 \\
\hline $\mathrm{DD}$ & 77 & $25.5 \%$ & 31 & $25.8 \%$ & & DD vs II & $0.966(0.536-1.738)$ & 0.907 \\
\hline \multicolumn{9}{|l|}{ ACE allele } \\
\hline 1 & 391 & $48.8 \%$ & 116 & $48.3 \%$ & - & \multirow[b]{2}{*}{ Dvs I } & $0.983(0.737-1.312)$ & \multirow[t]{2}{*}{0.909} \\
\hline D & 411 & $51.2 \%$ & 124 & $51.7 \%$ & - & & & \\
\hline \multicolumn{9}{|l|}{ AGTR1 genotype } \\
\hline$A A$ & 219 & $54.6 \%$ & 61 & $50.8 \%$ & \multirow[t]{3}{*}{0.73} & $C C+A C$ vs $A A$ & $0.859(0.571-1.293)$ & 0.466 \\
\hline$A C$ & 154 & $38.4 \%$ & 49 & $40.8 \%$ & & $C C$ vs $A C+A A$ & $0.826(0.389-1.753)$ & 0.618 \\
\hline CC & 28 & $7.0 \%$ & 10 & $8.4 \%$ & & CC vs AA & $0.780(0.359-1.694)$ & 0.529 \\
\hline \multicolumn{9}{|l|}{ AGTR1 allele } \\
\hline A & 592 & $73.8 \%$ & 171 & $71.3 \%$ & - & \multirow[t]{2}{*}{ Cvs A } & $0.879(0.638-1.212)$ & \multirow[t]{2}{*}{0.431} \\
\hline C & 210 & $26.2 \%$ & 69 & $28.8 \%$ & - & & & \\
\hline
\end{tabular}

aThe Chi-square test for difference in frequencies of 3 genotypes. ${ }^{\top}$ The Chi-square test for difference in frequencies of 2 genotypes, genotype groups or alleles. 'OR, 0.427 ; $95 \% \mathrm{Cl}, 0.245-0.742 ; P=0.0025$ in multivariable logistic regression model adjusted for age and sex.

Abbreviations: ACE, angiotensin-converting enzyme; AGT, angiotensinogen; AGTR1, angiotensin II receptor type 1; Cl, confidence interval; HF, heart failure; I/D, insertion/ deletion; $\mathrm{OR}$, odds ratio

Table 3. Association of G(-6)A AGT, I/D ACE, A1166C AGTR1 genotypes and LVMI in HF patients $(\mathrm{n}=401)$

\begin{tabular}{|c|c|c|c|c|}
\hline Polymorphism & LVMI, $\mathbf{g} / \mathbf{m}^{2}$ & $P$-value ${ }^{a}$ & Compared genotypes & $P$-value ${ }^{b}$ \\
\hline \multicolumn{5}{|l|}{ AGT genotype } \\
\hline GG & $126.2(94.6-153.6)$ & & $A A+G A$ vs $G G$ & 0.953 \\
\hline GA & $121.3(98.3-146.1)$ & 0.268 & $A A$ vs $G A+G G$ & 0.126 \\
\hline$A A$ & $132.8(103.2-152.9)$ & & AA vs GG & 0.315 \\
\hline \multicolumn{5}{|l|}{ ACE genotype } \\
\hline$\|$ & $126.1(99.3-150.0)$ & & $D D+I D$ vs II & 0.689 \\
\hline ID & $126.1(101.5-152.8)$ & 0.290 & DD vs ID + II & 0.116 \\
\hline DD & $118.8(96.2-141.0)$ & & DD vs II & 0.233 \\
\hline \multicolumn{5}{|l|}{ AGTR1 genotype } \\
\hline$A A$ & $121.4(100.7-145.4)$ & & $C C+A C$ vs $A A$ & 0.284 \\
\hline$A C$ & $132.5(99.8-155.6)$ & 0.241 & $C C$ vs $A C+A A$ & 0.357 \\
\hline CC & 116.9 (88.0-142.8) & & CC vs AA & 0.516 \\
\hline
\end{tabular}

LVMI is presented as median (IQR).

aThe Kruskal-Wallis test. ${ }^{\circ}$ The Mann-Whitney $\mathrm{U}$ test.

Abbreviations: see Table 1 and Table 2

The presence of the DD ACE genotype was significantly associated with a lower prevalence of $\mathrm{LVH}$ in patients with HFrEF (OR, 0.450 [95\%Cl 0.226-0.895]; $P=0.021)$. However, this association did not reach Bonferroni-corrected $P$-value threshold $(<0.0014)$.

\section{DISCUSSION}

This study evaluated the role of the G(-6)A AGT, I/D ACE and A1166C AGTR1 polymorphisms with HF and LVM in patients with HF. Although the association between the RAS polymorphisms and cardiovascular disease has been demonstrated in many previous studies, this relationship is still controversial. The importance of RAS polymorphisms in relation to HF has not been fully explained and is still widely discussed, and reports on these issues are contradictory. To our knowledge, this is the first cohort study that examined the association of the key RAS gene polymorphisms and HF and LVM in Polish patients. The present study demonstrated a correlation between $\mathrm{HF}$ and the AA genotype of the AGT gene.

Excessive circulating and tissue angiotensin II and aldosterone levels have been shown to lead to a profibrotic, proinflammatory, and prohypertrophic milieu that causes remodeling and dysfunction in cardiovascular and renal tissues [26]. Therefore, molecular variants of RAS are considered to be important for LVM, and thus, HF. To date, the relationship of M235T AGT polymorphism and HF was the most studied. It has been demonstrated that the con- 
Table 4. Association of G(-6)A AGT, I/D ACE, A1166C AGTR1 genotypes and LVH in HF patient group $(\mathrm{n}=401)$

\begin{tabular}{|c|c|c|c|c|c|c|c|c|}
\hline Polymorphism & \multicolumn{2}{|c|}{$\begin{array}{l}\text { Patients with LVH } \\
\qquad(\mathrm{n}=\mathbf{2 6 2})\end{array}$} & \multicolumn{2}{|c|}{$\begin{array}{l}\text { Patients without LVH } \\
\qquad(\mathrm{n}=139)\end{array}$} & $P$-value ${ }^{a}$ & $\begin{array}{c}\text { Compared genotypes } \\
\text { or alleles }\end{array}$ & OR $(95 \% \mathrm{CI})$ & P-value $^{\text {b }}$ \\
\hline \multicolumn{9}{|l|}{ AGT genotype } \\
\hline GG & 71 & $27.1 \%$ & 37 & $26.6 \%$ & \multirow[t]{3}{*}{0.23} & $A A+G A$ vs $G G$ & $0.976(0.613-1.553)$ & 0.918 \\
\hline GA & 134 & $51.6 \%$ & 81 & $58.3 \%$ & & $A A$ vs $G A+G G$ & $1.562(0.902-2.706)$ & 0.109 \\
\hline AA & 57 & $21.8 \%$ & 21 & $15.1 \%$ & & AA vs GG & $1.414(0.747-2.680)$ & 0.287 \\
\hline \multicolumn{9}{|l|}{ AGT allele } \\
\hline G & 276 & $52.7 \%$ & 155 & $55.8 \%$ & - & \multirow[t]{2}{*}{$A$ vs $G$} & $1.132(0.845-1.517)$ & \multirow[t]{2}{*}{0.405} \\
\hline A & 248 & $47.3 \%$ & 123 & $44.2 \%$ & - & & & \\
\hline \multicolumn{9}{|l|}{$A C E$ genotype } \\
\hline II & 62 & $23.7 \%$ & 30 & $21.6 \%$ & \multirow[t]{3}{*}{0.28} & $\mathrm{DD}+\mathrm{ID}$ vs II & $0.888(0.542-1.456)$ & 0.637 \\
\hline ID & 140 & $53.5 \%$ & 67 & $48.2 \%$ & & DD vs ID + II & $0.686(0.432-1.090)$ & 0.109 \\
\hline DD & 60 & $22.9 \%$ & 42 & $30.2 \%$ & & DD vs II & $0.828(0.619-1.109)$ & 0.205 \\
\hline \multicolumn{9}{|l|}{$A C E$ allele } \\
\hline 1 & 264 & $50.4 \%$ & 127 & $45.7 \%$ & - & \multirow[t]{2}{*}{ D vs I } & $0.828(0.619-1.109)$ & \multirow[t]{2}{*}{0.205} \\
\hline $\mathrm{D}$ & 260 & $49.6 \%$ & 151 & $54.3 \%$ & - & & & \\
\hline \multicolumn{9}{|l|}{ AGTR1 genotype } \\
\hline AA & 139 & $53.1 \%$ & 80 & $57.6 \%$ & \multirow[t]{3}{*}{0.49} & $C C+A C$ vs $A A$ & $1.200(0.793-1.817)$ & 0.389 \\
\hline$A C$ & 106 & $40.5 \%$ & 48 & $34.5 \%$ & & $C C$ vs $A C+A A$ & $0.807(0.367-1.775)$ & 0.594 \\
\hline$C C$ & 17 & $6.5 \%$ & 11 & $7.9 \%$ & & $C C$ vs $A A$ & $0.890(0.397-1.993)$ & 0.776 \\
\hline \multicolumn{9}{|l|}{ AGTR1 allele } \\
\hline$A$ & 384 & $73.2 \%$ & 70 & $25.2 \%$ & - & \multirow[t]{2}{*}{ C vs $A$} & $1.083(0.777-1.511)$ & \multirow[t]{2}{*}{0.637} \\
\hline C & 140 & $26.7 \%$ & 208 & $74.82 \%$ & - & & & \\
\hline
\end{tabular}

aThe Chi-square test for difference in frequencies of three genotypes. ${ }^{\mathrm{b}}$ The Chi-square test for difference in frequencies of two genotypes, genotype groups or alleles. Abbreviations: see Table 1 and Table 2

Table 5. Association of G(-6)A AGT, I/D ACE, A1166C AGTR1 genotypes and LVH in HF patients with reduced ejection fraction ( $\mathrm{n}=195)$

\begin{tabular}{|c|c|c|c|c|c|c|c|c|}
\hline Polymorphism & \multicolumn{2}{|c|}{$\begin{array}{l}\text { HFrEF patients } \\
\text { with LVH }(n=138)\end{array}$} & \multicolumn{2}{|c|}{$\begin{array}{l}\text { HFrEF patients } \\
\text { without LVH }(n=57)\end{array}$} & P-value $^{a}$ & $\begin{array}{c}\text { Compared genotypes } \\
\text { or alleles }\end{array}$ & OR $(95 \% \mathrm{CI})$ & $P$-value \\
\hline \multicolumn{9}{|l|}{ AGT genotype } \\
\hline GG & 36 & $26.1 \%$ & 13 & $22.8 \%$ & \multirow[t]{3}{*}{0.889} & $A A+G A$ vs $G G$ & $0.837(0.405-1.730)$ & 0.631 \\
\hline GA & 77 & $55.8 \%$ & 33 & $57.9 \%$ & & $A A$ vs $G A+G G$ & $0.925(0.421-2.034)$ & 0.847 \\
\hline$A A$ & 25 & $18.1 \%$ & 11 & $19.3 \%$ & & $A A$ vs $G G$ & $0.821(0.317-2.125)$ & 0.684 \\
\hline \multicolumn{9}{|l|}{$A G T$ allele } \\
\hline G & 149 & $54.0 \%$ & 59 & $51.8 \%$ & - & \multirow[t]{2}{*}{$A$ vs $G$} & $0.914(0.591-1.416)$ & \multirow[t]{2}{*}{0.688} \\
\hline A & 127 & $46.0 \%$ & 55 & $48.3 \%$ & - & & & \\
\hline \multicolumn{9}{|l|}{$A C E$ genotype } \\
\hline II & 38 & $27.5 \%$ & 11 & $19.3 \%$ & \multirow[t]{3}{*}{0.063} & $\mathrm{DD}+\mathrm{ID}$ vs II & $0.629(0.295-1.341)$ & 0.228 \\
\hline ID & 73 & $52.9 \%$ & 26 & $45.6 \%$ & & DD vs ID + II & $0.450(0.226-0.895)$ & 0.021 \\
\hline $\mathrm{DD}$ & 27 & $19.6 \%$ & 20 & $35.1 \%$ & & DD vs II & $0.391(0.161-0.948)$ & 0.035 \\
\hline \multicolumn{9}{|l|}{$A C E$ allele } \\
\hline I & 149 & $54.0 \%$ & 48 & $42.1 \%$ & - & \multirow[t]{2}{*}{ D vs I } & $0.620(0.399-0.963)$ & \multirow[t]{2}{*}{0.033} \\
\hline D & 127 & $46.0 \%$ & 66 & $57.9 \%$ & - & & & \\
\hline \multicolumn{9}{|l|}{ AGTR1 genotype } \\
\hline AA & 72 & $52.2 \%$ & 33 & $57.9 \%$ & \multirow[t]{3}{*}{0.632} & $C C+A C$ vs $A A$ & $1.260(0.676-2.350)$ & 0.466 \\
\hline$A C$ & 54 & $39.1 \%$ & 21 & $36.8 \%$ & & $C C$ vs $A C+A A$ & $1.714(0.465-6.320)$ & 0.413 \\
\hline $\mathrm{CC}$ & 12 & $8.7 \%$ & 3 & $5.3 \%$ & & CC vs $A A$ & $1.833(0.486-9.360)$ & 0.366 \\
\hline \multicolumn{9}{|l|}{ AGTR1 allele } \\
\hline A & 198 & $71.7 \%$ & 87 & $76.3 \%$ & - & \multirow[t]{2}{*}{ C vs A } & $1.269(0.766-2.103)$ & \multirow[t]{2}{*}{0.354} \\
\hline C & 78 & $28.3 \%$ & 27 & $23.7 \%$ & - & & & \\
\hline
\end{tabular}

aThe Chi-square test for difference in frequencies of three genotypes. ${ }^{\mathrm{b}}$ The Chi-square test for difference in frequencies of two genotypes, genotype groups or alleles. Abbreviations: HFrEF, HF patients with reduced ejection fraction; LVH, left ventricular hypertrophy; other, see Table 1 and Table 2

centration of $A G T$ in blood increases with the number of T235 alleles [27]. Some studies demonstrate that this single nucleotide polymorphism (SNP) of AGT may be associated with $\mathrm{HF}$ in different populations [27, 28], whereas some studies did not find associations between M235T AGT and $\mathrm{HF}[7,29]$. In our study, we examined the association between the $\mathrm{G}(-6) \mathrm{A} A G T$ polymorphism with $\mathrm{HF}$, and this polymorphism remains in very tight linkage disequilibrium with T235 AGT and marks the original form of the gene. The functionality of (-6G) AGT variants was demonstrated by their influence on the basal transcription rate [30]. In this study, we found association between $\mathrm{G}(-6)$ A of AGT and HF in our population, the analysis revealed the protective role of the homozygotes AA for HF. Additionally, we noted the 
lack of association of the I/D ACE and A1166C AGTR1 polymorphisms. The obtained result of the correlation of $(-6)$ AGT polymorphism with $\mathrm{HF}$ may result from the different concentration of AGT. Given the important role of $A G T$ in regulating RAS, it is likely that the $A G T$ polymorphism may modulate the risk of developing $\mathrm{HF}$ in the Polish population. However, these findings still need to be clarified.

The association between RAS polymorphisms and LVH has been demonstrated in numerous published studies [31, 32]. However, the relationship between these polymorphisms and LVM and HF is still not fully understood, and better understanding of the complexity of RAS should help modulate this system and consequently improve quality of life. As it is known, in the course of HF during pressure overload, there is myocardial remodeling, which leads to myocardial hypertrophy, as the result of adaptation to mechanical workload demands. However, under pathological conditions of the onset of $\mathrm{HF}$, myocardial remodeling reactions often become maladjusted, leading to myocardial decompensation. This phenomenon is associated with increased wall stress, insufficient or inappropriate cardiomyocyte hyperplasia, apoptosis or increased fibrosis [26].

In our study, we did not demonstrate any relationship between the RAS genes studied and LVM.

This relatively weak influence of genetic factors on LVM in our patients with $\mathrm{HF}$ may be due to a strong influence of risk factors of HF. In the Polish population, traditional risk factors for cardiovascular diseases (e.g., obesity, HT, diabetes mellitus, smoking, etc.) are still widespread, and as presented by Favé at al. [33], local environment directly influences disease-risk phenotypes and genetic variation, including fewer common variants, and can also modulate individual responses to environmental challenges. Previously, we presented a study in which we showed that $A C E$, $A T 1 R$ and MTHFR gene polymorphisms do not predispose to a greater LVM in Polish patients with myocardial infarction [34].

Furthermore, it should be noted that the patients in our program were treated for HF (mainly with ACE inhibitors, angiotensin receptor antagonists, calcium inhibitors, etc.), especially with drugs from the group of which RAS inhibitors may modulate LVM, which may have affected our results. It has been proven in numerous studies that the inhibition of the RAS as a result of the use of drugs from the group of ACE inhibitors influences the course of disease processes $[35,36]$.

Moreover, another study demonstrated a genetic influence of antihypertensive treatment and the effect of RAS blockers on the regression of LVH [37]. It is known that ACE inhibitors are among the basic drugs used in the treatment of patients with $\mathrm{HF}$ and asymptomatic left ventricular dysfunction, as they prevent disease progression, have protective effects of $\mathrm{LVH}$, and reduce mortality and the frequency of hospitalization [35].

Although RAS is an important contributor to LVM modulation, the contribution and serious consequences of $\mathrm{HT}$ should be considered. In our study, we did not observe the influence of the studied genes on LVM in patients with HF who also had $\mathrm{HT}$. We believe this finding can only confirm that proper treatment of $\mathrm{HT}$ can protect patients against myocardial hypertrophy. Many studies have shown that appropriate treatment of the effects of $\mathrm{HT}$ is associated with the regression of $\mathrm{LVH}[37,38]$; especially antihypertensive treatment with ACE inhibitors in patients with the DD genotype of the $A C E$ gene presenting the best response to $\mathrm{LVH}$ regression [39].

The limitation of this study is the relatively small study group. Moreover, the etiology of $\mathrm{HF}$ in the study group is diverse, which may affect the obtained results.

$\mathrm{HF}$ is a complex disease and the genetic components involved in its development are based on the action of many genes. Of particular note is LVH in the course of $\mathrm{HF}$, which is the main factor influencing the advancement of the disease process, and the exact mechanism of which is still not fully clear. As a result, the search for genes that can act as prognostic markers that could be used to predict poor outcomes and aid in selecting the appropriate therapeutic intervention is still ongoing. Further study on this complex system is necessary to improve medical therapies for cardiovascular diseases, allowing us to more adeptly modulate this system and improve clinical outcomes.

\section{CONCLUSIONS}

Our results suggested that polymorphism $\mathrm{G}(-6)$ A of the $A G T$ gene may play a protective role in the development of $\mathrm{HF}$ in Polish patients. However, further multi-center studies of ethnically diverse populations are needed to confirm this finding in the future.

\section{Article information}

Acknowledgments: This work was supported by internal funding from Pomeranian Medical University, Szczecin, Poland (to AC).

Conflict of interest: None declared.

Open access: This article is available in open access under Creative Common Attribution-Non-Commercial-No Derivatives 4.0 International (CC BY-NC-ND 4.0) license, allowing to download articles and share them with others as long as they credit the authors and the publisher, but without permission to change them in any way or use them commercially. For commercial use, please contact the journal office at kardiologiapolska@ptkardio.pl.

How to cite: Gorący I, Peregud-Pogorzelska M, Safranow K, et al. Key genetic variants in the renin-angiotensin system and left ventricular mass in a cohort of Polish patients with heart failure. Kardiol Pol. 2021; 79(7-8): 765-772, doi: 10.33963/KP.15989.

\section{REFERENCES}

1. Jackson G, Gibbs CR, Davies MK, et al. $A B C$ of heart failure. Pathophysiology. BMJ. 2000; 320(7228): 167-170, doi: 10.1136/bmj.320.7228.167, indexed in Pubmed: 10634740.

2. Gradman $\mathrm{AH}$, Alfayoumi F. From left ventricular hypertrophy to congestive heart failure: management of hypertensive heart disease. Prog Cardiovasc Dis. 2006; 48(5): 326-341, doi: 10.1016/j.pcad.2006.02.001, indexed in Pubmed: 16627048. 
3. Unger $T$. The role of the renin-angiotensin system in the development of cardiovascular disease. Am J Cardiol. 2002; 89(2A): 3A-9A; discussion 10A, doi: 10.1016/s0002-9149(01)02321-9, indexed in Pubmed: 11835903.

4. Buraczyńska M, Pijanowski Z, Spasiewicz D, et al. Renin-angiotensin system gene polymorphisms: assessment of the risk of coronary heart disease. Kardiol Pol. 2003; 58(1): 1-9, indexed in Pubmed: 14502296.

5. Robinson M, Williams SM. Role of two angiotensinogen polymorphisms in blood pressure variation. J Hum Hypertens. 2004; 18(12): 865-869, doi: 10.1038/sj.jhh.1001768, indexed in Pubmed: 15343353.

6. Pilbrow AP, Palmer BR, Frampton CM, et al. Angiotensinogen M235T and T174M gene polymorphisms in combination doubles the risk of mortality in heart failure. Hypertension. 2007; 49(2): 322-327, doi: 10.1161/01. HYP.0000253061.30170.68, indexed in Pubmed: 17145981.

7. Tiret $L$, Mallet $C$, Poirier $O$, et al. Lack of association between polymorphisms of eight candidate genes and idiopathic dilated cardiomyopathy: the CARDIGENE study. J Am Coll Cardiol. 2000; 35(1): 29-35, doi: 10.1016/s0735-1097(99)00522-7, indexed in Pubmed: 10636255.

8. Kim HS, Lee MM, Oh BH, et al. Synergistic effect of angiotensin-converting enzyme and angiotensinogen gene on cardiac hypertrophy. Int J Cardiol. 2000; 72(2): 151-161, doi: 10.1016/s0167-5273(99)00184-9, indexed in Pubmed: 10646957.

9. Wang AYM, Chan JCN, Wang M, et al. Cardiac hypertrophy and remodeling in relation to $A C E$ and angiotensinogen genes genotypes in Chinese dialysis patients. Kidney Int. 2003; 63(5): 1899-1907, doi: 10.1046/j.15231755.2003.00933.x, indexed in Pubmed: 12675870.

10. Yuan Y, Meng L, Zhou Y, et al. Genetic polymorphism of angiotensin-converting enzyme and hypertrophic cardiomyopathy risk: a systematic review and meta-analysis. Medicine (Baltimore). 2017; 96(48): e8639, doi: 10.1097/MD.0000000000008639, indexed in Pubmed: 29310338.

11. Dzida G, Sobstyl J, Puzniak A, et al. Polymorphisms of angiotensin-converting enzyme and angiotensin II receptor type 1 genes in essential hypertension in a Polish population. Med Sci Monit. 2001; 7(6): 1236-1241, indexed in Pubmed: 11687736.

12. Jastrzebska $M$, Widecka $K$, Ciechanowicz $A$, et al. Plasminogen activator inhibitor-1 (PAI-1) 4G/5G and angiotensin converting enzyme (ACE) I/D gene polymorphisms and fibrinolytic activity in patients with essential hypertension and dyslipidemia [article in Polish]. Pol Arch Med Wewn. 2005; 113(1): 7-20, indexed in Pubmed: 16130596.

13. Potaczek DP, Undas A, Iwaniec $T$, et al. The angiotensin-converting enzyme gene insertion/deletion polymorphism and effects of quinapril and atorvastatin on haemostatic parameters in patients with coronary artery disease. Thromb Haemost. 2005; 94(1): 224-225, indexed in Pubmed: 16116691.

14. Potaczek DP, Undas A, Celinska-Lowenhoff $M$, et al. The I allele of the angiotensin-converting enzyme gene polymorphism may determine an increase in homocysteine levels in fibrate-treated subjects. Cardiovasc Drugs Ther. 2006; 20(3): 229-232, doi: 10.1007/s10557-006-8374-8, indexed in Pubmed: 16779534.

15. Kryczka KE, Płoski R, Księżycka E, et al. The association between the insertion/deletion polymorphism of the angiotensin-converting enzyme gene and the plasma fibrinogen level in women and men with premature coronary artery atherosclerosis. Pol Arch Intern Med. 2020; 130(9): 748-756, doi: 10.20452/pamw.15461, indexed in Pubmed: 32584014.

16. Masuyer G, Schwager SLU, Sturrock ED, et al. Molecular recognition and regulation of human angiotensin-I converting enzyme (ACE) activity by natural inhibitory peptides. Sci Rep. 2012; 2: 717, doi: 10.1038/srep00717, indexed in Pubmed: 23056909.

17. Linhart A, Sedlácek K, Jáchymová M, et al. Lack of association of angiotensin-converting enzyme and angiotensinogen genes polymorphisms with left ventricular structure in young normotensive men. Blood Press. 2000; 9(1): 47-51, indexed in Pubmed: 10854008.

18. Estacio RO, Jeffers BW, Havranek EP, et al. Deletion polymorphism of the angiotensin converting enzyme gene is associated with an increase in left ventricular mass in men with type 2 diabetes mellitus. Am J Hypertens. 1999; 12(6):637-642, doi: 10.1016/s0895-7061(99)00013-8, indexed in Pubmed: 10371375.

19. Doolan G, Nguyen L, Chung J, et al. Progression of left ventricular hypertrophy and the angiotensin-converting enzyme gene polymorphism in hypertrophic cardiomyopathy. Int J Cardiol. 2004; 96(2): 157-163, doi: 10.1016/j.ijcard.2004.05.003, indexed in Pubmed: 15314809.
20. Karaali ZE, Agachan B, Yilmaz H, et al. Angiotensin-converting enzyme I/D gene polymorphisms and effects of left ventricular hypertrophy in Turkish myocardial infarction patients. Acta Cardiol. 2004; 59(5): 493-497, doi: 10.2143/AC.59.5.2005221, indexed in Pubmed: 15529552.

21. Oro C, Qian H, Thomas WG. Type 1 angiotensin receptor pharmacology: signaling beyond G proteins. Pharmacol Ther. 2007; 113(1): 210-226, doi: 10.1016/j.pharmthera.2006.10.001, indexed in Pubmed: 17125841.

22. López-Contreras J, Blanco-Vaca F, Borrás X, et al. Usefulness of the I/D angiotensin-converting enzyme genotype for detecting the risk of left ventricular hypertrophy in pharmacologically treated hypertensive men. J Hum Hypertens. 2000; 14(5): 327-331, doi: 10.1038/sj.jhh.1001005, indexed in Pubmed: 10822320.

23. Liu A, Wang S, Zhang C, et al. Role of angiotensin-converting enzyme insertion/deletion polymorphism in sudden cardiac arrest. J Cell Biochem. 2019; 120(3): 3474-3478, doi: 10.1002/jcb.27622, indexed in Pubmed: 30242890.

24. Lang RM, Bierig M, Devereux RB, et al. Chamber Quantification Writing Group, American Society of Echocardiography's Guidelines and Standards Committee, European Association of Echocardiography. Recommendations for chamber quantification: a report from the American Society of Echocardiography's Guidelines and Standards Committee and the Chamber Quantification Writing Group, developed in conjunction with the European Association of Echocardiography, a branch of the European Society of Cardiology. J Am Soc Echocardiogr. 2005; 18(12): 1440-1463, doi: 10.1016/j.echo.2005.10.005, indexed in Pubmed: 16376782.

25. Gorący I, Dawid G, Łoniewska B, et al. Genetics of the renin-angiotensin system with respect to cardiac and blood pressure phenotypes in healthy newborn infants. J Renin Angiotensin Aldosterone Syst. 2013; 14(4): 337347, doi: 10.1177/1470320312450531, indexed in Pubmed: 22772796.

26. Ames MK, Atkins CE, Pitt B. The renin-angiotensin-aldosterone system and its suppression. J Vet Intern Med. 2019; 33(2): 363-382, doi: 10.1111/jvim.15454, indexed in Pubmed: 30806496.

27. Zakrzewski-Jakubiak M, de Denus S, Dubé MP, et al. Ten renin-angiotensin system-related gene polymorphisms in maximally treated Canadian Caucasian patients with heart failure. Br JClin Pharmacol. 2008; 65(5): 742-751, doi: 10.1111/j.1365-2125.2007.03091.x, indexed in Pubmed: 18279468.

28. Imen T, Grissa MH, Boubaker H, et al. AGT M235t polymorphism and heart failure in a cohort of Tunisian population: diagnostic and prognostic value. Int J Clin Exp Med. 2015; 8(9): 16346-16351, indexed in Pubmed: 26629155.

29. Vancura V, Hubácek J, Málek I, et al. Does angiotensin-converting enzyme polymorphism influence the clinical manifestation and progression of heart failure in patients with dilated cardiomyopathy? Am J Cardiol. 1999; 83(3):461-462, A10, doi: 10.1016/s0002-9149(98)00889-3, indexed in Pubmed: 10072245.

30. Inoue I, Nakajima T, Williams CS, et al. A nucleotide substitution in the promoter of human angiotensinogen is associated with essential hypertension and affects basal transcription in vitro. J Clin Invest. 1997; 99(7): 1786-1797, doi: 10.1172/JCl119343, indexed in Pubmed: 9120024.

31. Fajar JK, Pikir BS, Sidarta EP, et al. The gene polymorphism of angiotensin-converting enzyme intron deletion and angiotensin-converting enzyme G2350A in patients with left ventricular hypertrophy: a meta-analysis. Indian Heart J. 2019; 71(3): 199-206, doi: 10.1016/j.ihj.2019.07.002, indexed in Pubmed: 31543192.

32. Bahramali E, Rajabi M, Jamshidi J, et al. Association of ACE gene D polymorphism with left ventricular hypertrophy in patients with diastolic heart failure: a case-control study. BMJ Open. 2016; 6(2): e010282, doi: 10.1136/bmjopen-2015-010282, indexed in Pubmed: 26861937.

33. Favé MJ, Lamaze FC, Soave D, et al. Gene-by-environment interactions in urban populations modulate risk phenotypes. Nat Commun. 2018; 9(1): 827, doi: 10.1038/s41467-018-03202-2, indexed in Pubmed: 29511166.

34. Goracy J, Peregud-Pogorzelska M, Goracy I, et al. Allelic variants of genes: angiotensin l-converting enzyme (ACE), angiotensin-II type 1 receptor (AT1R), methylenetetrahydrofolate reductase and left ventricular mass in patients with myocardial infarction [article in Polish]. Pol Arch Med Wewn. 2006; 115(2): 105-111, indexed in Pubmed: 17274465.

35. Ruggenenti P, lliev I, Costa GM, et al. Bergamo Nephrologic Diabetes Complications Trial Study Group. Preventing left ventricular hypertrophy by ACE inhibition in hypertensive patients with type 2 diabetes: a prespec- 
ified analysis of the Bergamo Nephrologic Diabetes Complications Trial (BENEDICT). Diabetes Care. 2008; 31(8): 1629-1634, doi: 10.2337/dc080371, indexed in Pubmed: 18443191.

36. Suzuki $\mathrm{H}$, Kanno $\mathrm{Y}$, Ikeda $\mathrm{N}$, et al. Selection of the dose of angiotensin converting enzyme inhibitor for patients with diabetic nephropathy depends on the presence or absence of left ventricular hypertrophy. Hypertens Res. 2002; 25(6): 865-873, doi: 10.1291/hypres.25.865, indexed in Pubmed: 12484510.

37. Ahmed SN, Jhaj R, Sadasivam B, et al. Regression of the left ventricular hypertrophy in patients with essential hypertension on standard drug therapy. Discoveries (Craiova). 2020; 8(3): e115, doi: 10.15190/d.2020.12, indexed in Pubmed: 33102689.

38. Dawson A, Morris AD, Struthers AD. The epidemiology of left ventricular hypertrophy in type 2 diabetes mellitus. Diabetologia. 2005; 48(10): 19711979, doi: 10.1007/s00125-005-1896-y, indexed in Pubmed: 16094529.

39. Nakayama M, Nakano H, Tsuboi N, et al. The effect of angiotensin receptor blockade ARB on the regression of left ventricular hypertrophy in hemodialysis patients: comparison between patients with $D$ allele and non-D allele ACE gene polymorphism. Clin Nephrol. 2005; 64(5): 358-363, doi: 10.5414/cnp64358, indexed in Pubmed: 16312263. 